\title{
Solitary Nodular Pure Bronchioloalveolar Carcinoma
}

\author{
Marc Pusztaszeri ${ }^{a} \quad$ Maria-Victoria Orcurto $^{b}$ Sabine Schmidt ${ }^{c}$ \\ Thorsten Krueger ${ }^{\mathrm{d}}$ \\ ${ }^{\text {a Pathology }}{ }^{\mathrm{b}}$ Nuclear Medicine, ${ }^{\mathrm{C}}$ Radiology and ${ }^{\mathrm{d}}$ Thoracic Surgery Divisions, Centre Hospitalier Universitaire \\ Vaudois (CHUV), Lausanne, Switzerland
}

A 75-year-old female nonsmoker was investigated for an ovarian mass. A CT scan showed a $1.8-\mathrm{cm}$ incidental nodule in the right upper lobe (posterior segment), with spiculated borders, reaching the pleura. Its center was discretely excavated. PET/CT fusion, CT and PET scan showed faint FDG uptake by the nodule (fig. 1). Following a CT-guided biopsy of the nodule, a right upper lobe resection was performed. Macroscopic examination showed a 1.4- $\mathrm{cm}$ subpleural nodule with well-defined but irregular borders (fig. 2). It was histologically diagnosed as a pure nonmucinous bronchioloalveolar carcinoma (BAC) (fig. 3). The patient was alive without signs of tumor recurrence 6 months later. BAC is known for low FDG uptake presumed to be secondary to the lower proliferation rate of these tumors [1]. Particularly low metabolic activity is observed in pure BAC, unifocal and mucin-containing tumors [2]. Furthermore, in small lesions activity is underestimated due to partial volume effect.
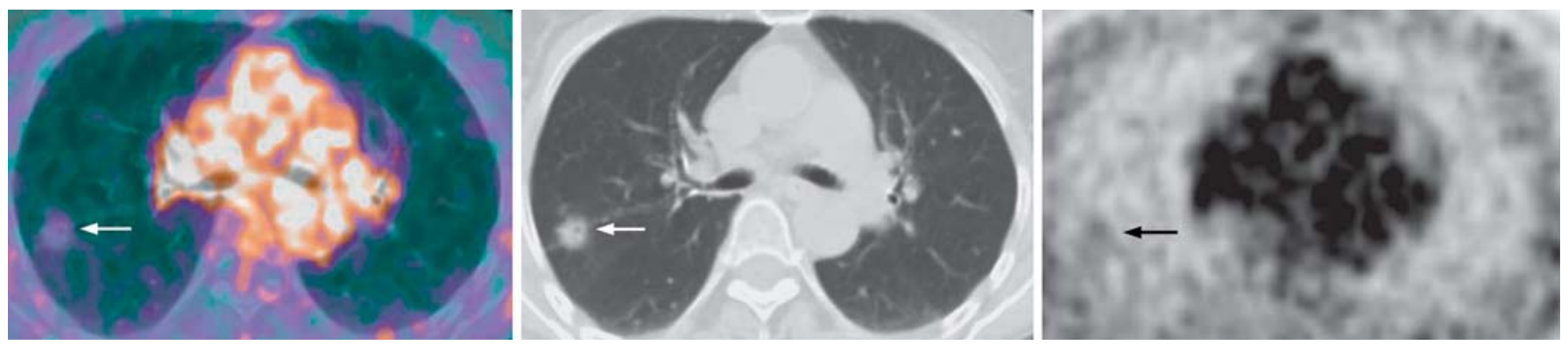

Fig. 1. Axial images of PET/CT fusion, CT and PET showing only faint FDG uptake by the nodule (arrow) identified on CT. Standardized uptake values $\left(\mathrm{SUV}_{\max }\right)$ of the nodule and normal lung parenchyma were 0.9 and 0.6 $\mathrm{g} / \mathrm{ml}$, respectively.

\section{KARGER}

Fax +41613061234 E-Mail karger@karger.ch www.karger.com
Marc Pusztaszeri

Institute of Pathology, Centre Hospitalier Universitaire Vaudois (CHUV) Rue du Bugnon

$\mathrm{CH}-1011$ Lausanne (Switzerland)

Tel. +41 2131429 54, Fax +41 2131471 15, E-Mail Marc.Pusztaszeri@chuv.ch 


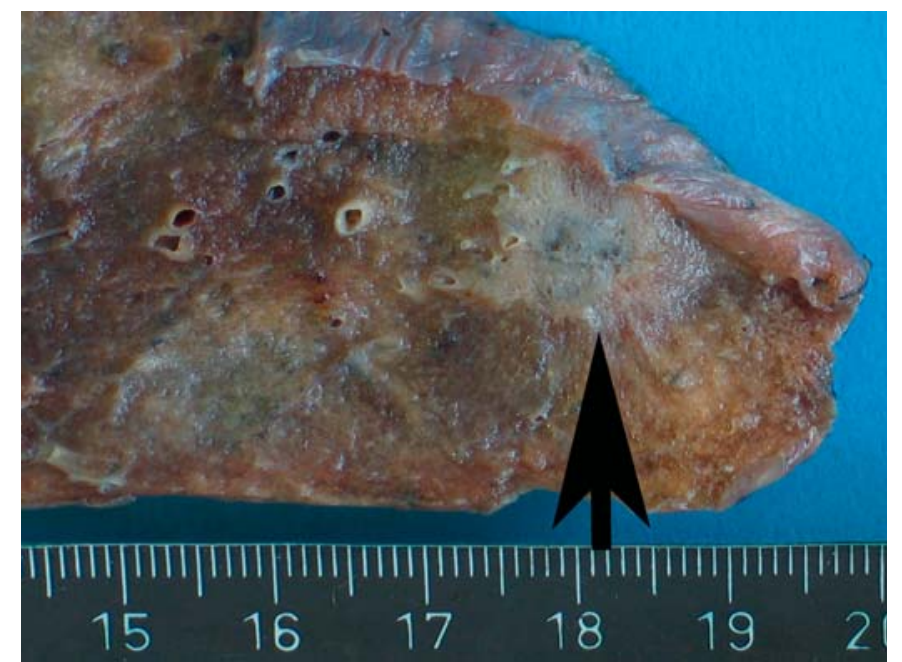

Fig. 2. Macroscopy of the nodule (arrow).

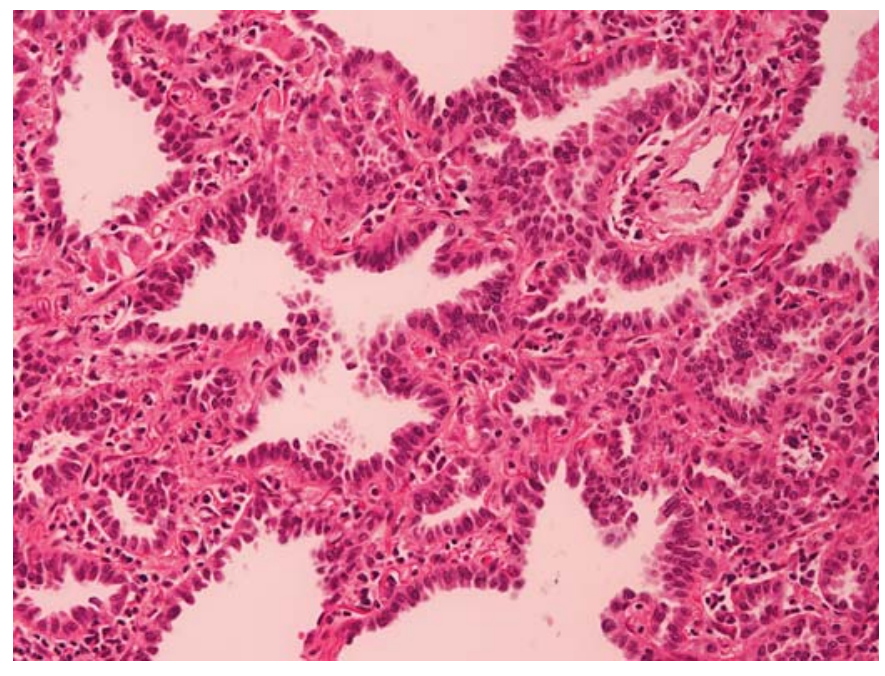

Fig. 3. Histology of the nodule showing atypical nonmucinous cells growing exclusively along the lining of the alveolar walls.

\section{References}

1 Raz DJ, Kim JY, Jablons DM: Diagnosis and treatment of bronchioloalveolar carcinoma. Curr Opin Pulmon Med 2007;13:290-296.
-2 Yap CS, Schiepers C, Fishbein MC, et al: FDG-PET imaging in lung cancer: how sensitive is it for bronchioloalveolar carcinoma? Eur J Nucl Med Mol Imaging 2002;29:11661173. 